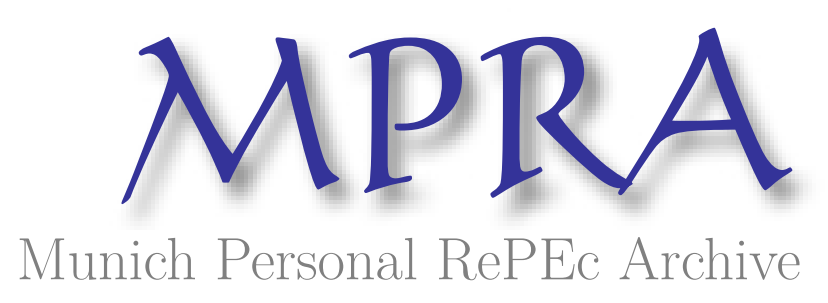

\title{
Index Option Returns from an Anchoring Perspective
}

\author{
Hammad, Siddiqi
}

1 June 2015

Online at https://mpra.ub.uni-muenchen.de/65331/

MPRA Paper No. 65331, posted 30 Jun 2015 14:32 UTC 


\title{
Index Option Returns from an Anchoring Perspective
}

\author{
Hammad Siddiqi ${ }^{1}$ \\ The University of Queensland \\ h.siddiqi@uq.edu.au
}

June 2015

Using leverage adjusted index option data, a novel prediction of the anchoring adjusted option pricing model is tested. The anchoring model is based on the idea that the risk of the underlying stock is used as a starting point that gets adjusted upwards to estimate call option risk. The anchoring heuristic implies that such adjustments are insufficient leading to underestimation of option risk. The prediction of the anchoring model is strongly supported in the data spanning nearly 26 years. Furthermore, the anchoring model is shown to be consistent with the key features observed in the data.

JEL Classification: G13, G02

Keywords: Anchoring, Option Pricing, Leverage Adjusted Returns, Option Mispricing, Behavioral Finance

\footnotetext{
${ }^{1}$ I am grateful to John Quiggin, Simon Grant, Begona Dominguez, and seminar participants in the University of Queensland macro-finance workshop for helpful comments and suggestions. All errors and omissions are author's responsibility. A previous version of the paper was circulated with the title, "Analogy Making and the Puzzles of Index Option Returns".
} 


\section{Index Option Returns from an Anchoring Perspective}

Statistical inference with index option returns is difficult due to the highly volatile, non-linear and skewed nature of such returns. Constantinides, Jackwerth, and Savov (2013) construct a panel of leverage adjusted returns (with targeted market beta of one) from S\&P 500 index options. Portfolios are constructed separately for call and put options. An option portfolio is constructed by combining an index option (either call or put) with a risk-free asset in such a manner that the weight on the option is equal to its inverse price elasticity with respect to the underlying index value. Such leverage adjustment, aimed at achieving a market beta of one, reduces the variance and skewness and renders the returns close to normal.

Table 1 presents the summary statistics of the leverage adjusted returns (Table 3 from Constantinides et al (2013)). As can be seen, six features stand out in the data: 1) Leverage adjusted call returns are lower than the average index return. 2) Leverage adjusted call returns fall with the ratio of strike to spot. 3) Leverage adjusted put returns are typically higher than the index average return. 4) Leverage adjusted put returns also fall with the ratio of strike to spot. 5) At higher strikes (out-of-the-money call range), leverage adjusted call returns increase as time to expiry increases. 6) At lower strikes (in-the-money put range), leverage adjusted put returns fall as time to expiry increases.

The above features are sharply inconsistent with the Black-Scholes/Capital Asset Pricing Model prediction that all leverage adjusted returns must be equal to the index average return, and should not vary with the ratio of strike to spot or expiry. Using their dataset, Constantinides et al (2013) reject the Capital Asset Pricing Model. Assuming that all risks are correctly priced, they empirically estimate a variety of two factor models. They find that either one of two crisis related factors (Jump and Volatility Jump) along with the market reasonably explains the cross-section of leverage adjusted returns. 
Table 1 (Table 3 from Constantinides et al (2013))

\begin{tabular}{|c|c|c|c|c|c|c|c|c|c|c|c|c|}
\hline \multicolumn{13}{|c|}{$\begin{array}{l}\text { Average } \mathrm{p} \\
\text { January } 2 \\
\text { period. }\end{array}$} \\
\hline \multirow[b]{2}{*}{$\mathrm{K} / \mathrm{S}$} & \multicolumn{6}{|c|}{ Call } & \multicolumn{6}{|c|}{ Put } \\
\hline & 90 & $95 \%$ & $100 \%$ & $105 \%$ & $110 \%$ & Hi-Lo & 90 & $95 \%$ & $100 \%$ & $105 \%$ & $110 \%$ & Hi-Lo \\
\hline \multicolumn{13}{|c|}{ Average monthly returns } \\
\hline 30 days & 0.49 & 0.42 & 0.21 & \begin{tabular}{|l|}
0.03 \\
\end{tabular} & -0.02 & -0.51 & 2.18 & 1.66 & 1.07 & 0.80 & 0.75 & -1.43 \\
\hline (s.e) & 0.24 & 0.24 & 0.24 & 0.23 & 0.22 & 0.17 & 0.36 & 0.32 & 0.29 & 0.27 & 0.26 & 0.20 \\
\hline 90 days & 0.51 & 0.44 & 0.37 & \begin{tabular}{|l|}
0.31 \\
\end{tabular} & 0.21 & -0.30 & 1.15 & 1.10 & 0.91 & 0.81 & 0.74 & -0.40 \\
\hline (s.e) & 0.24 & 0.24 & 0.24 & 0.24 & 0.24 & 0.11 & 0.33 & 0.31 & 0.29 & 0.27 & 0.27 & 0.14 \\
\hline $90-30$ & 0.03 & 0.02 & 0.16 & \begin{tabular}{|l|}
0.28 \\
\end{tabular} & 0.23 & & -1.04 & -0.55 & -0.16 & 0.00 & -0.01 & \\
\hline (s.e) & 0.02 & 0.02 & 0.03 & 0.06 & 0.11 & & 0.11 & 0.07 & 0.03 & 0.02 & 0.02 & \\
\hline
\end{tabular}

Empirical estimation of risk factors is based on the belief that all risks are correctly priced.

The task then falls on the asset pricing branch of finance to provide a theoretical justification for the estimated risk factors. However, a large body of literature departs from the assumption that all risks are correctly priced and argues that biases matter. Shefrin and Statman (1994) put forward a structured behavioral framework for capital asset pricing theory that allows for systematic treatment of various biases.

One bias which features quite prominently in recent empirical literature on financial markets is anchoring. Anchoring is based on the observation that while forming estimates, people tend to start from an initial value (either self-generated or implied by the environment) and then make adjustments to it to form their judgments. Anchoring implies that such adjustments are often insufficient (Kahneman and Tversky (1974)) with judgment remaining biased towards the initial value known as the anchor. In the literature, both cognitive and computational reasons for insufficient adjustments have been identified (Epley and Gilovich (2006)). See Furnham and Boo (2011) for a literature review on anchoring. A sample of recent empirical work on anchoring in financial markets includes, Baker, Pan, and Wurgler (2012) who show that recent peak prices of target firms become anchors in mergers and acquisitions, and Douglas, Engelberg, Parsons, and Van 
Wesep (2015) who show that the current spread paid by a firm seems to be anchored to the credit spread the firm had paid earlier. Earlier arguments for the centrality of anchoring in understanding financial market behavior have been made in Hirshleifer (2001) and Shiller (1999).

Allowing for proportional transaction costs, Siddiqi (2015) puts forward an option pricing model that incorporates the role of anchoring in option pricing. The model is based on the idea that the risk of the underlying stock is used as a starting point that gets adjusted upwards to estimate call option risk, with the anchoring heuristic leading to insufficient adjustment. Hence, call option risk is underestimated.

In this article, I show that all of the key features of leverage adjusted returns mentioned above are consistent with the anchoring model in Siddiqi (2015). Furthermore, I derive a new prediction of the anchoring model and use the dataset developed in Constantinides et al (2013) to test it. I find that the prediction is strongly supported in the data. To my knowledge, this is first empirical paper on the relevance of the anchoring heuristic for option risk judgment and consequently its price.

In this article, to my knowledge, I provide first ever empirical evidence in favor of anchoring heuristic influencing option risk judgment and consequently its price. However, there is strong prior experimental and anecdotal evidence. In particular, experimental findings in Rockenbach (2004), Siddiqi (2012), and Siddiqi (2011) can be interpreted as due to anchoring. They find that the hypothesis that a call option is priced by equating its expected return to that of the underlying stock return outperforms other pricing hypotheses. Plausibly, if the risk of the underlying stock is used as a starting point which is then insufficiently adjusted to arrive at call option risk then call returns would not deviate from stock returns as much as they should. Furthermore, it is quite common to find market professionals with decades of experience arguing that a call option is a surrogate for the underlying stock. ${ }^{2}$ This is a strong indication that they do not consider risk of call to be substantially different from the risk of the underlying stock.

\footnotetext{
${ }^{2}$ As illustrative examples, see the following: http://finance.yahoo.com/news/stock-replacement-strategy-reduce-risk-142949569.html http://ezinearticles.com/?Call-Options-As-an-Alternative-to-Buying-the-Underlying-Security\&id=4274772, http://www.investingblog.org/archives/194/deep-in-the-money-options/ http://www.triplescreenmethod.com/TradersCorner/TC052705.asp, http://daytrading.about.com/od/stocks/a/OptionsInvest.htm
} 
This article is organized as follows. Section 1 shows that key features of leverage adjusted call option returns are consistent with the anchoring model. Section 2 shows that the key features of leverage adjusted put returns are consistent with the anchoring model. Section 3 puts forward a novel prediction of the anchoring model. Section 4 presents the results of testing the novel prediction with the dataset developed in Constantinides et al (2013). Section 5 concludes.

\section{Anchoring and Leverage Adjusted Call Returns}

As can be seen from Table 1, the two key features of (leverage adjusted) call option returns are:

1) Call returns are lower than average index returns, and 2) Call return falls as the ratio of strike to spot increases.

In this section, I show that both these features are consistent with the anchoring model in Siddiqi (2015).

It is useful to begin by summarizing the essential argument in Siddiqi (2015). This is done in section 1.1, which is based on Siddiqi (2015).

\subsection{The Anchoring Adjusted Option Pricing Model}

The central prediction of asset pricing theory is:

$E\left[R_{i}\right]=R_{F}-\frac{1}{E\left[u^{\prime}\left(c_{t+1}\right)\right]} \operatorname{Cov}\left[u^{\prime}\left(c_{t+1}\right), R_{i}\right]$

Where $R_{i}$ and $R_{F}$ denote the return on a risky asset and the return on the risk free asset respectively. Equation (1.1) shows that the return that a subjective expected utility maximizer expects from a risky asset depends on his belief about the covariance of the asset's return with his marginal utility of consumption.

According to (1.1), an investor is required to form a judgment about the covariance of an asset's return with his marginal utility of consumption. Siddiqi (2015) argues that instead of forming risk judgments in isolation for each asset; such a judgment is formed for a more familiar asset and 
then extrapolated to another similar asset. A call option derives its existence from the underlying stock, and their payoffs are strongly related and move together.

Following Siddiqi (2015), if one forms a judgment about call option risk in comparison with his judgment about the underlying stock risk, then one may write:

$\operatorname{Cov}\left(\frac{u^{\prime}\left(c_{t+1}\right)}{E\left[u^{\prime}\left(c_{t+1}\right)\right]}, R_{c}\right)=\operatorname{Cov}\left(\frac{u^{\prime}\left(c_{t+1}\right)}{E\left[u^{\prime}\left(c_{t+1}\right)\right]}, R_{s}\right)+A$

Where $R_{C}$ and $R_{S}$ are call and stock returns respectively, and $A$ is the adjustment used to arrive at call option risk from the underlying stock risk. Almost always, assets pay more (less) when consumption is high (less), hence, the covariance between an asset's return and marginal utility of consumption is typically negative. That is, $\operatorname{Cov}\left(\frac{u^{\prime}\left(c_{t+1}\right)}{E\left[u^{\prime}\left(c_{t+1}\right)\right]}, R_{s}\right)<0$. So, in order to make a call option at least as risky as the underlying stock, $A \leq 0$.

In contrast, option pricing theory predicts that, if risks are correctly perceived:

$$
\operatorname{Cov}\left(\frac{u^{\prime}\left(c_{t+1}\right)}{E\left[u^{\prime}\left(c_{t+1}\right)\right]}, R_{c}\right)=\pi \cdot \operatorname{Cov}\left(\frac{u^{\prime}\left(c_{t+1}\right)}{E\left[u^{\prime}\left(c_{t+1}\right)\right]}, R_{s}\right)
$$

Where $\pi>1$ and typically takes very large values. That is, typically $\pi \gg 1$. To appreciate, the difference between (1.3) and (1.2), note that under the Black Scholes assumptions, $\pi=\Omega$, which is call price elasticity w.r.t the underlying stock price. $\Omega$ takes very large values, especially for out-ofthe-money call options. That is $\operatorname{Cov}\left(\frac{u^{\prime}\left(c_{t+1}\right)}{E\left[u^{\prime}\left(c_{t+1}\right)\right]}, R_{s}\right)$ is likely to be a far bigger negative number with correct risk judgment than with anchoring. Hence, a comparison of (1.2) and (1.3) indicates that, with anchoring, one underestimates the option risk.

Substituting (1.2) in (1.1) leads to:

$E\left[R_{C}\right]=E\left[R_{S}\right]+|A|$

In contrast, substituting (1.3) in (1.1) under the Black Scholes assumptions yields:

$E\left[R_{C}\right]=R_{F}+\Omega \cdot\left(E\left[R_{S}\right]-R_{F}\right)$

$\Omega>1$ and typically takes very large values (typically varies from 3 to 35 for index options). Hence, expected call return is likely to be smaller with anchoring when compared with the Black-Scholes 
predictions. Note that (1.4) and (1.5) are equal if $|A|=(\Omega-1)\left(E\left[R_{S}\right]-R_{F}\right)$. So, the presence of the anchoring bias means that $|A|<(\Omega-1)\left(E\left[R_{S}\right]-R_{F}\right)$.

Anchoring leads to expected call option return given in (1.4). For a call option with strike $K$, over a small time interval, $d t,(1.4)$ can be written as (with proportional transaction costs):

$\frac{1}{d t} \cdot \frac{E[d C]}{(1+\theta) C}=\frac{1}{d t} \cdot \frac{E[d S]}{(1+\theta) S}+\left|A_{K}\right|$

Where $C, S$, and $\theta$ denote call price, stock price, and percentage transaction cost respectively, where $\left|A_{K}\right|$ is the adjustment made by the marginal investor in options to form call risk judgment starting from the underlying stock risk.

The underlying stock price is assumed to follow geometric Brownian motion:

$d S=\mu S d t+\sigma S d Z$

Where $d Z$ is the standard Guass-Weiner process.

If the risk free rate is $r$ and the risk premium on the underlying stock is $\delta$, then, $\frac{1}{d t} \frac{E[d S]}{S}=\mu=r+$ $\delta$. Hence, (1.6) may be written as:

$\frac{1}{d t} \frac{E[d C]}{C}=\left(r+\delta+\left|A_{K}\right|(1+\theta)\right)$

From Ito’s lemma:

$E[d C]=\left(\mu S \frac{\partial C}{\partial S}+\frac{\partial C}{\partial t}+\frac{\sigma^{2} S^{2}}{2} \frac{\partial^{2} C}{\partial S^{2}}\right) d t$

Substituting (1.8) in (1.7) leads to:

$\left(r+\delta+\left|A_{K}\right|(1+\theta)\right) C=\frac{\partial C}{\partial t}+\frac{\partial C}{\partial S}(r+\delta) S+\frac{\partial^{2} C}{\partial S^{2}} \frac{\sigma^{2} S^{2}}{2}$

(1.9) describes the partial differential equation (PDE) that must be satisfied if anchoring determines call option prices. 
To appreciate the difference between anchoring PDE and the Black-Scholes PDE, consider the expected return under the Black-Scholes approach (with zero transaction cost), which is given in (1.5). Over a small time interval, $d t$, one may re-write (1.5) as:

$\frac{1}{d t} \cdot \frac{E[d C]}{C}=r+\Omega \cdot(\mu-r)$

Substituting (1.8) in (1.10) and realizing that $\Omega=\frac{S}{C} \frac{\partial C}{\partial S}$ leads to the following:

$r C=\frac{\partial C}{\partial t}+r S \frac{\partial C}{\partial S}+\frac{\partial^{2} C}{\partial S^{2}} \frac{\sigma^{2} S^{2}}{2}$

(1.11) is the Black-Scholes PDE.

Note that the anchoring PDE in (1.9) converges to the Black-Scholes PDE in (1.11) if there are no transaction costs and the risk adjustment is correct. That is, when $\theta=0$ and $|A|=$ $(\Omega-1)(\delta)$.

The anchoring PDE is solved in Siddiqi (2015) to obtain the following price of a European call option:

$C=e^{-\left|A_{K}\right|(1+\theta)(T-t)}\left\{S N\left(d_{1}^{A}\right)-K e^{-(r+\delta)(T-t)} N\left(d_{2}^{A}\right)\right\}$

$d_{1}^{A}=\frac{\ln (S / K)+\left(r+\delta+\frac{\sigma^{2}}{2}\right)(T-t)}{\sigma \sqrt{T-t}}, d_{2}^{A}=\frac{\ln \left(\frac{S}{K}\right)+\left(r+\delta-\frac{\sigma^{2}}{2}\right)(T-t)}{\sigma \sqrt{T-t}}$

$0 \leq\left|A_{K}\right|<\left(\Omega_{K}-1\right) \delta$

Next, I show what leverage adjustment means for anchoring adjusted option prices.

\subsection{Leverage Adjusted Option Returns with Anchoring}

Applying leverage adjustment to a call option means creating a portfolio consisting of the call option and a risk-free asset in such a manner that the weight on the option is $\Omega_{K}^{-1}$. It follows that the leverage adjusted call option return is:

$\Omega_{K}^{-1} \cdot \frac{1}{d t} \cdot E \frac{[d C]}{C}+\left(1-\Omega_{K}^{-1}\right) r$ 
For simplicity, and without relevance to the results presented here, I assume that the transaction costs are zero. Substituting from (1.7) and realizing that anchoring implies that $\left|A_{K}\right|=$ $m \cdot\left(\Omega_{K}-1\right) \delta$ where $0 \leq m<1,(1.13)$ can be written as:

$\delta\left\{m \cdot\left(1-\Omega_{K}^{-1}\right)+\Omega_{K}^{-1}\right\}+r$

From (1.14) one can see that as the ratio of strike to spot rises, leverage adjusted call return must fall. This is because $\Omega_{K}$ rises with the ratio of strike to spot $\left(\Omega_{K}^{-1}\right.$ falls).

Note that call price elasticity w.r.t the underlying stock price under the anchoring model is:

$\Omega_{K}=\frac{s}{\left(S N\left(d_{1}^{A}\right)-K e^{-(r+\delta)(T-t)} N\left(d_{2}^{A}\right)\right)} \cdot N\left(d_{1}^{A}\right)$

Substituting (1.15) in (1.14) and simplifying leads to:

$R_{L C}=\mu-\delta \cdot \frac{K}{S} \cdot e^{-(r+\delta)(T-t)} \cdot \frac{N\left(d_{2}^{A}\right)}{N\left(d_{1}^{A}\right)} \cdot(1-m)$

$R_{L C}$ denotes the expected leverage adjusted call return with anchoring. Note if $m=1$, then the leverage call return is equal to the CAPM/Black-Scholes prediction, which is $R_{L C}=\mu$.

Proposition 1. Leverage adjusted call option return with anchoring is less than the average underlying return. Furthermore, it must fall as the ratio of strike to spot increases.

\section{Proof.}

See Appendix A.

As proposition 1 shows, anchoring model's predictions are consistent with the first two features observed in the data as mentioned in the introduction. That is, not only index call return should be lower than the average index return, it must also fall as the ratio of strike to spot increases. Note, it does not matter what the expected return from a call option is, as long as there is anchoring bias, 
that is, as long as $m<1$, it follows that leverage adjusted call returns must fall as the ratio of strike to spot to increases.

Figure 1 plots the returns with 1, 2, and 3 months to expiry $(r=2 \%, \delta=5 \%, \sigma=20 \%)$. From Table 1 in the introduction, one can see that as expiry increases, leverage adjusted call returns rise sharply for out-of-the-money range. Figure 1 shows that as time to expiry increases, leverage adjusted call returns with anchoring should rise and quite prominently so at higher strikes. Hence, the anchoring model not only predicts that returns must be lower than average index returns and must fall as strike to spot rises, but it is also consistent with returns rising sharply with expiry at higher strikes. This match between the model's predictions and the data is quite intriguing.

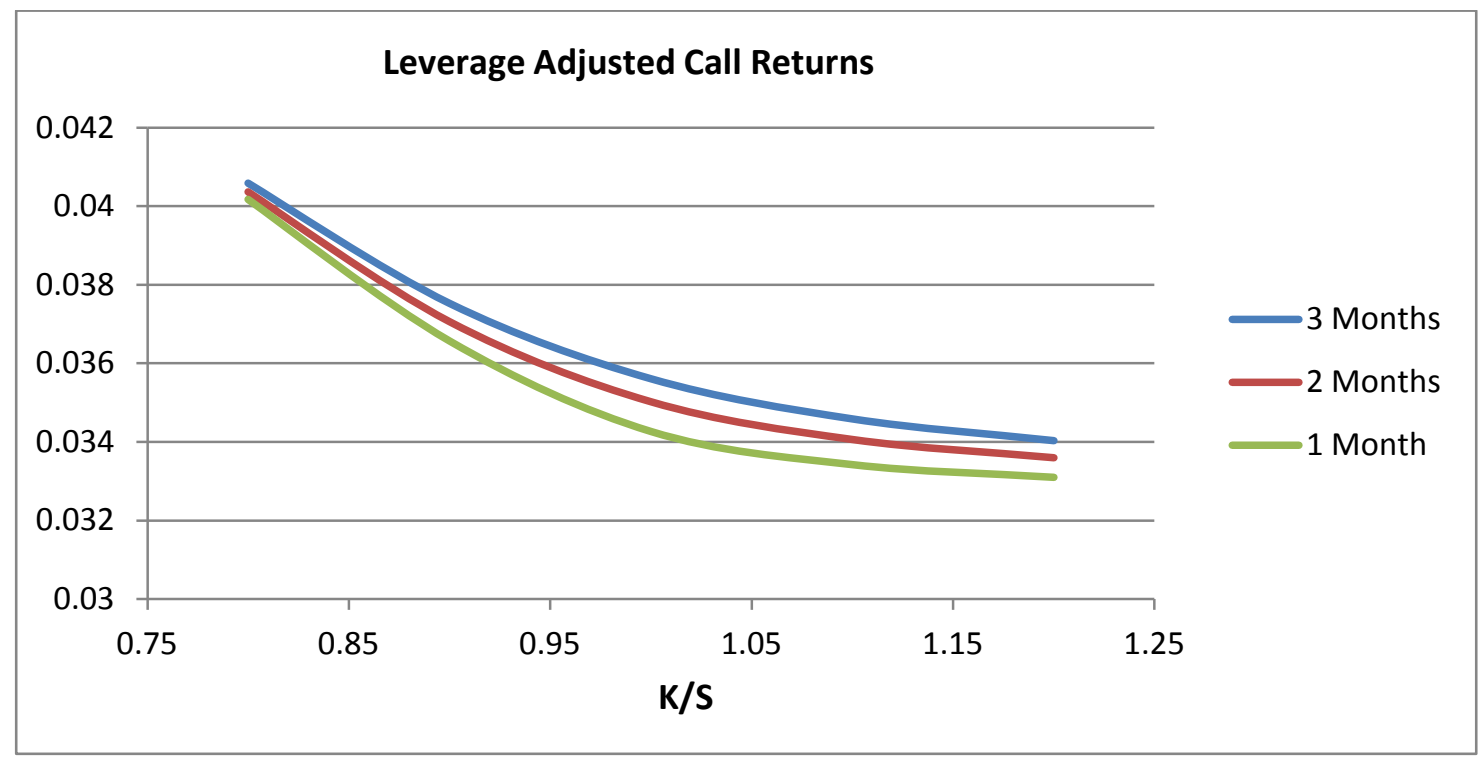

Figure 1

Next section shows that the anchoring model's predictions about leverage adjusted put returns are also spot on.

\section{Anchoring and Leverage Adjusted Put Returns}

As can be seen from Table 1, the two key features of (leverage adjusted) put option returns are:

1) They are larger than the average index return, and 2) They fall as the ratio of strike to spot increases. 
In this section, I show that both of the above features follow from the anchoring model.

By using put-call parity, the following price for a European put option is derived in Siddiqi (2015):

$K e^{-r(T-t)}\left\{1-e^{-\delta(T-t)} N\left(d_{2}^{A}\right) e^{-\left|A_{K}\right|(1+\theta)(T-t)}\right\}-S\left(1-e^{-\left|A_{K}\right|(1+\theta)(T-t)} N\left(d_{1}^{A}\right)\right)$

Ignoring transaction costs, and by using the same logic as in the previous section, the leverage adjusted put option return with anchoring can be shown to be as follows:

$R_{L P}=\mu+\delta \cdot \frac{K}{S} \cdot e^{-(r+\delta)(T-t)} \cdot \frac{e^{-\left|A_{K}\right|(T-t)} \cdot N\left(d_{2}^{A}\right)}{\left(1-e^{-\left|A_{K}\right|(T-t)} N\left(d_{1}^{A}\right)\right)} \cdot(1-m)$

As can be seen from the above equation, the CAPM/Black-Scholes prediction of $R_{L P}=\mu$ is a special case with $m=1$. That it, the CAPM/Black-Scholes prediction follows if there is no anchoring bias.

Proposition 2. The leverage adjusted put return with anchoring must be larger than the average underlying return. Furthermore, it must fall as the ratio of strike to spot increases.

Proof.

See Appendix B.

Figure 2 plots the leverage adjusted put returns for 1, 2, and 3 months to expiry $(r=2 \%, \delta=$ $5 \%, \sigma=20 \%)$. 


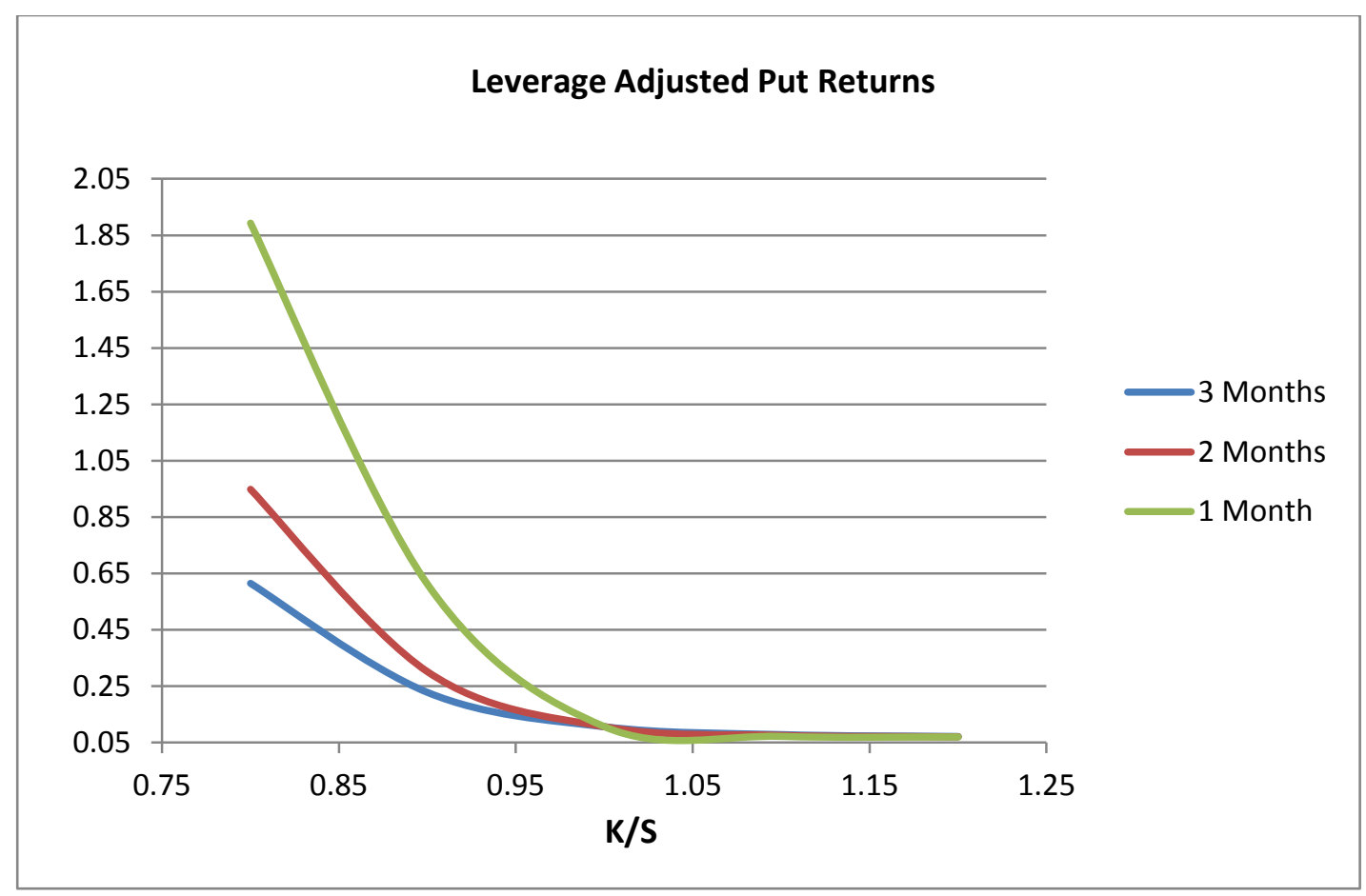

Figure 2

Figure 2 shows that leverage adjusted put returns fall quite sharply as expiry increases at lower strikes. This is consistent with the findings in Table 1. The predictions of the anchoring model regarding leverage adjusted put returns are in agreement with the data.

It is quite interesting that the key features of leverage adjusted returns (for both call and put options) are in accordance with the anchoring model. The anchoring model provides closed-form solutions for call and put option price. Hence, it is possible to test for a novel prediction of the anchoring model. This is done in the next section.

\section{A Novel Prediction of the Anchoring Model}

By using the anchoring model, expressions for leverage adjusted call and put returns are derived in the previous two sections. It turns out that the anchoring model makes a novel prediction regarding the difference between leverage adjusted put and call returns. Intuitively, the prediction can be seen in Figures 1 and 2. Figure 2 shows that leverage adjusted put returns fall sharply as the ratio of strike to spot increases at lower strikes and are flatter at higher strikes, whereas Figure 1 shows that 
leverage adjusted call returns fall with the ratio of strike to spot. It follows that the difference between leverage adjusted put and call returns must fall as the ratio of strike to spot increases at lower strikes if the anchoring model is correct.

Formally, subtracting (2.2) from (1.16) yields:

$R_{L P}-R_{L C}=\frac{K}{S} \cdot \delta \cdot e^{-(r+\delta)(T-t)}\left\{\frac{N\left(d_{2}^{A}\right)(1-m)}{\left(1-e^{-\left|A_{K}\right|(T-t)} \cdot N\left(d_{1}^{A}\right)\right) \cdot N\left(d_{1}^{A}\right)}\right\}$

As can be seen from (3.1), the CAPM/Black-Scholes prediction of $R_{L P}-R_{L C}=0$ is obtained if there is no anchoring bias. That is, if $m=1$.

Proposition 3. The difference between the leverage adjusted put and call returns must fall as the ratio of strike to spot increases if $K \leq S$.

Proof.

See Appendix C.

In the next section, I use the dataset developed in Constantinides et al (2013) to test this prediction.

\section{Empirical Findings}

Constantinides et al (2013) use Black-Scholes elasticities evaluated at implied volatility for constructing leverage adjusted returns. As the anchoring model elasticities are very close to BlackScholes elasticities evaluated at implied volatility, the dataset can be used to test the prediction of the anchoring model. The dataset used in this paper is available at http://www.wiwi.unikonstanz.de/fileadmin/wiwi/jackwerth/Working Paper/Version325 Return Data.txt 
The construction of this dataset is described in detail in Constantinides et al (2013). It is almost 26 years of monthly data on leverage adjusted S\&P-500 index option returns ranging from April 1986 to January 2012.

Wilcoxon signed rank test is used as it allows a direct observation by observation comparison of two time series. The following procedure is adopted:

1) The dataset has the following ratios of strikes to spot: $0.9,0.95,1.0,1.05$, and 1.10. For each value of strike to spot, the difference between leverage adjusted put and call returns is calculated.

2) Pair-wise comparisons are made between time series of 0.9 and 0.95, 0.95 and 1.0, 1.0 and 1.05, and 1.05 and 1.10. Such comparisons are made for each level of maturity: 30 days, 60 days, or 90 days.

3) The first time series in each pair is dubbed series1, and the second time series in each pair is dubbed series 2. That is, for the pair, 0.9 and 0.95, 0.9 is Series 1, and 0.95 is Series 2.

4) For each pair, if the prediction is true, then Series $1>$ Series 2 . This forms the alternative hypothesis in the Wilcoxon signed rank test, which is tested against the null hypothesis: Series $1=$ Series 2

Table 2 shows the results. As can be seen from the table, when call is in-the-money, the difference between leverage adjusted put and call returns falls with strike to spot at all levels of expiry (Series 1 is greater than Series 2). Hence, null hypothesis is rejected, in accordance with prediction of the anchoring model. As expected, the p-values are quite large for out-of-the-money call range, so null cannot be rejected for out-of-the-money call range. 


\begin{tabular}{|c|c|c|c|}
\hline & \multicolumn{2}{|c|}{ Table 2 } \\
\hline Put minus Call Return (Monthly) & Put minus Call Return (Monthly) & Maturity (days) & Wilcoxon Signed Rank Test \\
\hline $\begin{array}{c}\text { Leverage Adjusted } \\
\text { (April 1986 to January 2012) }\end{array}$ & $\begin{array}{c}\text { Leverage Adjusted } \\
\text { (April 1986 to January 2012) }\end{array}$ & & Null Hypothesis: Series 1=Series 2 \\
\hline Series 1 Strike (\%spot) & Series 2 Strike (\%spot) & & Plternate Hypothesis: Series 1>Series 2 \\
\hline & & & $5.62883 \mathrm{E}-14$ \\
\hline 0.9 & 0.95 & 30 & $2.33147 \mathrm{E}-14$ \\
\hline 0.95 & 1 & 30 & 0.095264801 \\
\hline 1 & 1.05 & 30 & 0.378791967 \\
\hline 1.05 & 1.1 & 30 & $2.23715 \mathrm{E}-06$ \\
\hline 0.9 & 0.95 & 60 & $2.08904 \mathrm{E}-11$ \\
\hline 1 & 1 & 60 & $1.31059 \mathrm{E}-09$ \\
\hline 1.05 & 1.05 & 60 & 0.978440796 \\
\hline 0.9 & 1.1 & 60 & 0.002029759 \\
\hline 1 & 0.95 & 90 & $2.84604 \mathrm{E}-08$ \\
\hline 1.95 & 1 & 90 & 0.10253709 \\
\hline
\end{tabular}

Hence, the results are in strong agreement with the prediction of the anchoring model. As seen in the previous sections, the anchoring model performs remarkably well in generating the key features observed in the data. In this section, a novel prediction of the anchoring model is shown to be strongly supported in the data.

\section{Conclusions}

Empirical work on option pricing typically assumes that all risks are correctly priced and then proceeds to estimate various risk factors. State of the art models typically estimate risks due to jumps, stochastic volatility, and jumps in volatility. This article challenges the assumption that all risks are correctly priced by showing that the anchoring adjusted option pricing model developed in Siddiqi (2015) performs remarkably work when tested with index option data. It shows that not only the key features in the data are consistent with the anchoring model, but also a novel prediction of the anchoring model is strongly supported in the data. 


\section{References}

Baker, M., Pan X., and Wurgler, J. (2012), “The Effect of Reference Point Prices on Mergers \& Acquisitions”, Journal of Financial Economics, 106, No. 1, pp. 49-71.

Campbell, S. D., and Sharpe, S. A. (2009), "Anchoring bias in consensus forecast and its effect on market prices", Journal of Financial and Quantitative Analysis, Vol. 44, pp. 369-90.

Cen L., Hilary F., and Wei, J. (2013), “The role of anchoring bias in the equity market: Evidence from analysts' earnings forecasts and stock returns", Journal of Financial and Quantitative Analysis, Vol. 48, Issue 1, pp. 47-76.

Constantinides, G. M., Jackwerth, J. C, and Savov A. (2013), “The Puzzles of Index Option Returns”, Review of Asset Pricing Studies, Advanced Access Published May 27, 2013.

Douglas, C., Engelberg, J., Parsons, C. A., Van Wesep, E. D. (2015), “Anchoring on credit spreads”. The Journal of Finance, doi:10.1111/jofi.12248

Epley, N., and Gilovich, T. (2006), "The anchoring-and-adjustment heuristic: Why the adjustments are insufficient". Psychological Science, No. 4, pp. 311-318.

Furnham, A., Boo, H.C., 2011. "A literature review of the anchoring effect.” The Journal of Socio-Economics 40, 35-42. doi: 10.1016/j.socec.2010.10.008.

Hirshleifer, D. (2001), "Investor Psychology and Asset Pricing”, Journal of Finance, Vol. LVI, No, 4, pp. 15331597.

Johnson, J., Liu, S., and Shnytzer, A. (2009), "To what extent do investors in a financial market anchor their judgment? Evidence from the Hong Kong horse-race betting market", Journal of Behavioral Decision Making, Vol. 24, No. 2, pp. 410-434.

Kahneman, D., and Tversky, A. (1974), "Judgment under uncertainty: Heuristics in biases". Science, Vol. 185, No. 4157, pp. 1124-1131.

Kaustia, Markku and Alho, Eeva and Puttonen, Vesa, How Much Does Expertise Reduce Behavioral Biases? The Case of Anchoring Effects in Stock Return Estimates. Financial Management, Vol. 37, No. 3, pp. 391 411, Autumn 2008. Available at SSRN: http://ssrn.com/abstract $=1066641$

Rockenbach, B. (2004), “The Behavioral Relevance of Mental Accounting for the Pricing of Financial Options”. Journal of Economic Behavior and Organization, Vol. 53, pp. 513-527.

Shefrin, H. and Statman, M. (1994), "Behavioral Capital Asset Pricing Theory", Journal of Financial and Quantitative Analysis, Vol. 29, Issue 3, pp. 323-349.

Shiller, Robert J., 1999. "Human behavior and the efficiency of the financial system," Handbook of Macroeconomics, in: J. B. Taylor \& M. Woodford (ed.), Handbook of Macroeconomics, edition 1, volume 1, chapter 20, pages 1305-1340 Elsevier.

Siddiqi, H. (2015), “Anchoring Heuristic in Option Pricing”, May (2015). Available at SSRN: http://ssrn.com/abstract $=2584839$ or http://dx.doi.org/10.2139/ssrn.2584839 
Siddiqi, H. (2012), “The Relevance of Thinking by Analogy for Investors' Willingness to Pay: An Experimental Study", Journal of Economic Psychology, Vol. 33, Issue 1, pp. 19-29.

Siddiqi, H. (2011), "Does Coarse Thinking Matter for Option Pricing? Evidence from an Experiment" IUP Journal of Behavioral Finance, Vol. VIII, No.2. pp. 58-69

Siddiqi, H. (2009), "Is the Lure of Choice Reflected in Market Prices? Experimental Evidence based on the 4Door Monty Hall Problem". Journal of Economic Psychology, April.

\section{Appendix A}

By direct observation, it follows that $R_{L C}<\mu$.

For variation with respect to $K / S$ :

$\frac{\partial R_{L C}}{\partial(K / S)}=-\frac{\delta e^{-(r+\delta)(T-t)} N\left(d_{2}^{A}\right)}{N\left(d_{1}^{A}\right) \cdot \sigma \sqrt{T-t}}\left\{\sigma \sqrt{T-t}-\left(\frac{N^{\prime}\left(d_{2}^{A}\right)}{N\left(d_{2}^{A}\right)}-\frac{N^{\prime}\left(d_{1}^{A}\right)}{N\left(d_{1}^{A}\right)}\right)\right\}$

As $\left\{\sigma \sqrt{T-t}-\left(\frac{N^{\prime}\left(d_{2}^{A}\right)}{N\left(d_{2}^{A}\right)}-\frac{N^{\prime}\left(d_{1}^{A}\right)}{N\left(d_{1}^{A}\right)}\right)\right\}>0$, it follows:

$\frac{\partial R_{L C}}{\partial(K / S)}<0$

\section{Appendix B}

It follows from direct observation that $R_{L P}>0$.

For simplicity, the following proof is shown for the case when $m=0$. The proof is easily extendable to higher values of $m$ by a similar logic.

The partial derivative with respect to $K / S$ :

$\frac{\partial\left(R_{L P}\right)}{\partial(K / S)}=\delta e^{-(r+\delta)(T-t)} \cdot \frac{N\left(d_{2}^{A}\right)}{\left(1-N\left(d_{1}^{A}\right)\right)} \cdot \frac{1}{\sigma \sqrt{T-t}}\left\{\sigma \sqrt{T-t}-\left(\frac{N^{\prime}\left(d_{2}^{A}\right)}{N\left(d_{2}^{A}\right)}+\frac{N^{\prime}\left(-d_{1}^{A}\right)}{N\left(-d_{1}^{A}\right)}\right)\right\}$

As $\frac{N^{\prime}\left(d_{2}^{A}\right)}{N\left(d_{2}^{A}\right)}>-d_{2}^{A}$ and $\frac{N^{\prime}\left(-d_{1}^{A}\right)}{N\left(-d_{1}^{A}\right)}>d_{1}^{A}$, it follows:

$\left\{\left(\frac{N^{\prime}\left(d_{2}^{A}\right)}{N\left(d_{2}^{A}\right)}+\frac{N^{\prime}\left(-d_{1}^{A}\right)}{N\left(-d_{1}^{A}\right)}\right)\right\}>d_{1}^{A}-d_{2}^{A}=\sigma \sqrt{T-t}$

Hence, $\frac{\partial\left(R_{L P}\right)}{\partial(K / S)}<0$. 


\section{Appendix C}

For simplicity, the proof is shown for the case when $m=0$. The proof is easily extendable to other values of $m$ by a similar logic.

$R_{L P}-R_{L C}=\frac{K}{S} \cdot \delta \cdot e^{-(r+\delta)(T-t)}\left\{\frac{N\left(d_{2}^{A}\right)}{\left(1-N\left(d_{1}^{A}\right)\right) \cdot N\left(d_{1}^{A}\right)}\right\}$

$\frac{\partial\left(R_{L P}-R_{L C}\right)}{\partial(K / S)}=\delta \cdot e^{-(r+\delta)(T-t)}\left\{\frac{N\left(d_{2}^{A}\right)}{\left(1-N\left(d_{1}^{A}\right)\right) \cdot N\left(d_{1}^{A}\right)}\right\} \cdot \frac{1}{\sigma \sqrt{T-t}} \cdot\left\{\sigma \sqrt{T-t}-\left(\frac{N^{\prime}\left(d_{2}^{A}\right)}{N\left(d_{2}^{A}\right)}+\frac{N^{\prime}\left(-d_{1}^{A}\right)}{N\left(-d_{1}^{A}\right)}-\frac{N^{\prime}\left(d_{1}^{A}\right)}{N\left(d_{1}^{A}\right)}\right)\right\}$

For $K<S,\left\{\sigma \sqrt{T-t}-\left(\frac{N^{\prime}\left(d_{2}^{A}\right)}{N\left(d_{2}^{A}\right)}+\frac{N^{\prime}\left(-d_{1}^{A}\right)}{N\left(-d_{1}^{A}\right)}-\frac{N^{\prime}\left(d_{1}^{A}\right)}{N\left(d_{1}^{A}\right)}\right)\right\}<0$.

Hence, $\frac{\partial\left(R_{L P}-R_{L C}\right)}{\partial(K / S)}<0$ if $K<S$. 